irrigated with water brought from considerable distances along skilfully aligned channels. They demarcate their village boundaries and recognise rights of property in land. They are skilled in weaving, make fairly good pottery, extract salt from brine wells, work up imported iron into weapons and implements, and are adepts in mat and basket weaving. Still, in spite of these advances towards civilisation, they practised up to quite recent times the brutal custom of head-hunting. As connected with their funereal rites this mav be piacular, propitiatory, or both. It seems reasonable to suppose that, like the $\mathrm{Wa}$ of Burma, they procure heads in the hope that the soul of the victim will accompany his skull, and that when hung up in the house of its possessor this will act as a guardian against the powers of evil, the skull of a stranger being preferred, because the ghost does not know its way about, and is less likely to wander. Mr. Hodson has done good service in pointing out how the custom is connected with the blood feud, with funerary rites and eschatological beliefs, and that it has a social side as a proof of fitness for initiation into the tribe. Hence it is often encouraged by women, who laugh at young men appearing at the village festivals without the decoration which marks the successful warrior.

Mr. Hodson's careful review of the tribal and village customs, particularly the institution of taboos and the use of the communal house for males, superstitions, and religious beliefs, a survey largely based on personal intercourse with the tribe, forms an important contribution to the ethnology of India.

\section{THE PENNY: A SUGGESTION.}

$\mathrm{D}$

EAR old penny! You have been with me all my life. You were the first present I ever had, and when I was young your potentiality was great. You would buy everything a boy required-peg-tops, jam tarts, kites, marbles, or a bun. As I grew older I recognised that your purchasing power did not keep pace with my desires. Still, you do something-you give me a paper, a box of matches, or carry me long distances on trams or buses. With two or three pennies in my pocket I feel armed against emergencies. You will dry an urchin's tears or give comfort to a beggar. You have been and still remain a friend to young and old.

But with all your virtues you have still some drawbacks. I think you are susceptible of great improvement.

The ordinary person likes you in twos or threes, but in quantity he calls you "coppers." When in this form, the young lady in the shop frequently apologises -not for you so much, as for her inability to represent you by some other coin.

Forty-eight coppers, so says the law, weigh one pound; but nobody, whatever his vocation may be, cares to carry a pound, whether it be represented by forty-eight pennies or a lump of brass in his pocket. Not only would they weigh him down, but possibly they might spoil his figure. From the legal definition you should weigh one-third of an ounce, or $145^{\circ} 8333$ grains. The latter number frightens me; it is indefinite and without end. It means nothing for common use. To carry about a weight which cannot be used to weigh anything in particular, not even a letter, is not practical. It is silly. If our penny could be made to weigh a little bit less but remain commensurable with an ounce, even if a hole was bored through its centre to reduce its weight, which would tell you what it was by its feel, the Chancellor of the Exchequer would, by the saving in metal, certainly be possessed of wealth equal to the fees of No. 2163 , VOL. 86] many Baronetcies. The public would have less load to carry, and rich and poor would have in their pockets a useful standard of weight.

As I am now finding fault, let me next ask whether you measure anything in particular. In your modern form, so far as I know, there is as little respectability in your dimensions as in your weight.

A penny is one out of a number of little discs that can be economically stamped out of a sheet of bronze. We are told that a bit of metal goes through rolls, which are so wonderfully adjusted that the resultant strips or "fillets" do not vary more than I/IO,000 part of an inch in their thickness. This suggests that the authors of the penny wished it to possess an accuracy bordering on the supernatural. But the subsequent punching, pressing, and milling has apparently done much to destroy their good intentions.

When you, little penny, entered the world, you were bright and shiny, with all the lustre, and colour of burnished gold; but your guinea-like look never lasted more than a few short weeks. You quickly became the microbic-covered old brown copper. You look round, you are supposed to be round, but are you really round?

Many times per day somebody or other wishes to draw a circle, puts you on a piece of paper, and scratches a pencil round your edge. Now and then the housewife puts you on a piece of linen to mark out buttonholes or points for decoration. The results look excellent, and satisfy many purposes, but a pair of callipers show that you have more than one diameter. The least diameter of our world runs from the north pole to the south, but if the north pole of a penny is Britannia's head and the fringes of her skirts the south, this is your longest diameter. Poor old penny, your dimensions have been made opposite to those of the world in which you circulate. The world is world-shaped, and you are penny-shaped. You only possess an average diameter, which is not an inch or an inch and a quarter, neither does it appear to be related to any everyday unit of linear measure. Your dimensions, like your weight, suggest an oversight on the part of your creators. You are lopsided and measure nothing in particular.

As you exist at the present day you measure a tiny little bit more than one inch and one-fifth. Why "the tiny little bit" exists, I and my friends connected with minting cannot tell. Knock it off, and the Exchequer would increase its capital without extra taxation, and five pennies would measure exactly six inches.

But reformation should go still farther, and the diameter of a penny, if possible, be made to measure something more definite by itself. If the halfpenny, which does measure one inch, stands in the way, do not disgrace it, but reduce it to another standard.

Our poor dumb friend, not only because it neither possesses a useful weight or measure, has been compelled to take a back place in numismatic competitions, but it has had to put up with a bit of extra weight in the form of an inscription. On one side of our penny we see a statement in abbreviated Latin which tells us that the Ruling Monarch is a defender of the faith. With this the penny gives us something to think about both day and night, and to many the statement may be regarded as in keeping with its weight and measure. On the reverse, we see a bravelooking, long-limbed lady sitting on a chariot, one wheel of which appears to be elliptical. I have been quite curious about this personage, and with the help of a magnifying glass have compared her face as shown on pennies and halfpennies. As a result of my examination I conclude there are at least two types of Britannia. The aristocratic, with a Grecian nose, and the democratic, with a nez retroussé. Possibly 
the differences may be due to pressing, punching, or to wear and tear.

Therefore you are, dear old penny, from my point of view simply a token, without definite weight, definite dimensions, and with a variable expression.

The Spanish "penny" is marked ten grammes, and it also reads Ioo pieces make one kilo. The "halfpenny" weighs 5 grammes, and, like the larger coin, is largely used for purposes of weighing. These coins also have useful dimensions.

If Britannia could be induced to sit a little more forward on her shield, with thîs and other slight adjustments, the penny would have a definite centre of gravity, and be of use as a plumb-bob, or as a pendulum in our board schools. With properly spaced milling on its edge, pennies could be used by Boy Scouts as angle measurers or rough protractors. When drawing plans, with one penny, and another to buy a compass, he could tell the time, or without a compass and with a watch he would know his bearings. With a piece of thread, a pebble for a weight, and a penny a clinometer could be made.

Whether any of these suggestions could possibly be carried out in practice remains for the consideration of the controllers of our coinage. A penny has had an up and down time of it. It has been altered often, and why not once again. The Romans possibly were too proud to accept small change, which, when handed to them, they flicked off the counter with the back of a finger, remarking "Romanus sum." At all events Roman coins seem to have been scattered over countries where Romans once resided, and now their coins are among the most common evidences of their former occupation. Six hundred years ago, when the penny was made of silver, it would pay a wage or buy a horse. Now it is only a little brown token. If the Chancellor of the Exchequer could see how to cut off "the little bit," make "the little hole" and use a less expensive metal the penny would be reincarnated, become the admiration of the world, taxation would be relieved, and Lloyd George worshipped. But do not forget to treat other tokens as you would the penny. Make them more cheaply and increase their usefulness.

John Milne.

\section{THE BRITISH SCIENCE GUILD.}

THE fifth annual meeting of the guild was held at the Mansion House on April 7, under the presidency of the Lord Mayor. There was a fairly good attendance, and the number of well-known leaders in the field of technical and scientific education was large. Sir William White presented the annual report, and referred to the progress made during the year in various directions. Of the special activities of the guild, he mentioned the work of the subcommittees upon agricultural education, the proposed museum at South Kensington for the physical and mechanical sciences, medical education, and the relation of the Imperial College of Science and Technology with the University of London. From the annual report itself we learn that committees have also been investigating the problems involved in the conservation of natural sources of energy and the coordination of charitable effort. The guild has further benefited science and the community by its successful action in regard to the site of the Solar Physics Observatory; the existence of the science section at the Japan-British Exhibition, and the inclusion of a similar section in the plans for the forthcoming Coronation Exhibition, are also in large measure due to the guild's influence.

The features of the vear's progress which Sir William White emphasised were the improved attitude of the Government towards agricultural research, and the greater readiness of Government departments generally to seek the advice of highly qualified men of science. In certain instances this readiness led to the appointment of consultative committees, which were acting in an advisory capacity to several departments. At the same time, Prof. R. A. Gregory's report showed how much more was being done in other countries to promote research. The organisation of the Canadian Committee has made good progress, and its first annual report has been issued. The spread of evening classes and the movement in favour of continued education are hopeful indications of the public recognition of the value of technical instruction.

Lord Haldane thought that the technical education which was at present being given in England was underrated. In higher education, in the application of science to industry, Germany had marked features which we did not possess; but evening schools and classes connected with the universities or great technical colleges were little known in Germany. Technical teaching had developed in a very striking way in London and throughout the United Kingdom. It was not without result. The quality of British goods commanded the respect of the world. Science was present in every corner of the Sheffield factories in which engines of war-offensive and defensive-were being constructed. Our Government was a very unscientific-looking machine, but it was being substantially and rapidly improved every year. There was far more intercommunication between various Government offices than was generally supposed. He hoped to see remarkable developments before long in the domain of public health.

We cannot refrain from expressing our regret that Lord Haldane should have dwelt so strongly on the merits of our evening-class system without qualifying his praise of this system by some mention of its inevitable shortcomings. The Technical Education Committee of the guild views the matter in a different light. This committee presented a very valuable report, and we quote from the last sentences preceding the recommendations which it contains :-

Most of the technical instruction carried on in Great Britain is evening-class work. The committee, however, are strongly of opinion that day work is of infinitely greater value than work done in the evenings, when neither instructor nor student can possibly be at their best; consequently, evening work cannot be compared for thoroughness and efficiency with such day-class work as is done in the German, and in some of our higher, technical institutes. Until this is recognised, it is impossible for this country to expect to compete technically with other countries. (The italics are our own.)

There are valuable contributions appended to this committee's report by Dr. H. T. Bovey, Prof. Meldola, Dr. Pohl, Prof. Gregory, and Prof. Perry. The lastnamed awards an overdue meed of praise to the toobelittled work of the Science and Art Department, and has a word of encouragement for workers in evening classes, but he adds a strong appeal to employers to allow apprentices to attend science classes "during the regular working hours" (the italics are Prof. Perry's). It is evident from these reports that the guild is doing more than interest public men and impress them with the importance of scientific method, for through its committees it is doing the spade-work essential to the conversion of aspiration into practice. It is to be regretted, however, that no mention is made of the Education (Choice of Employment) Act which was passed in November, 1910. Though this may appear to be a very modest piece of legislation, it may well prove to be the starting point of national and No. $2 \mathrm{I} 63$, VOL. 86] 